\title{
Using the institutional grammar tool to understand regulatory compliance: The case of Colorado aquaculture
}

\author{
Saba Siddiki \\ School of Public and Environmental Affairs, Indiana University-Purdue University Indianapolis, Indianapolis, \\ IN, USA
}

Xavier Basurto

Duke Marine Lab, Duke University, Beaufort, NC, USA

Christopher M. Weible

School of Public Affairs, University of Colorado Denver, Denver, CO, USA

\begin{abstract}
What is the relationship between the design of regulations and levels of individual compliance? To answer this question, Crawford and Ostrom's institutional grammar tool is used to deconstruct regulations governing the aquaculture industry in Colorado, USA. Compliance with the deconstructed regulatory components is then assessed based on the perceptions of the appropriateness of the regulations, involvement in designing the regulations, and intrinsic and extrinsic motivations. The findings suggest that levels of compliance with regulations vary across and within individuals regarding various aspects of the regulatory components. As expected, the level of compliance is affected by the perceived appropriateness of regulations, participation in designing the regulations, and feelings of guilt and fear of social disapproval. Furthermore, there is a strong degree of interdependence among the written components, as identified by the institutional grammar tool, in affecting compliance levels. The paper contributes to the regulation and compliance literature by illustrating the utility of the institutional grammar tool in understanding regulatory content, applying a new Q-Sort technique for measuring individual levels of compliance, and providing a rare exploration into feelings of guilt and fear outside of the laboratory setting.
\end{abstract}

Keywords: deconstructing rules, institutional grammar tool, Q-Sort, regulatory compliance, regulatory design.

\section{Introduction}

Understanding the extent of compliance with regulations has long been a challenge in the study of governance. The challenge partly entails developing a systematic deconstruction of the written components (e.g. target populations, requirements, sanctions, conditions) within the regulations. Such regulatory components can be extensive, multifaceted, and

Correspondence: Saba Siddiki, School of Public and Environmental Affairs, Indiana UniversityPurdue University Indianapolis, 801 W. Michigan Street, BS 3027, Indianapolis, IN 46202, USA. Email: ssiddiki@iupui.edu

Accepted for publication 1 December 2011. 
interactive by comprising dozens to hundreds of statements that forbid, permit, and require specific actions by targeted populations under certain situations. Another part of the challenge involves the applicability of the regulatory components with the contextual situations. Some regulations are locally tailored and perceived as appropriate to the contextual situations faced by the targeted actors, which, at least hypothetically, increase the possibility of compliance (Ostrom 2005). Additionally, regulatory compliance takes place among people making decisions based on intrinsic motivations (e.g. feelings of guilt) and extrinsic motivations (e.g. formal sanctions) (Becker 1968; Zimring \& Hawkins 1973; Grasmick \& Bursik 1990). Integrating these different parts of the challenge in understanding compliance and regulations, this paper seeks to contribute to knowledge about compliance by analyzing the written components within regulations in conjunction with perceived regulatory appropriateness, involvement in designing the regulations, and intrinsic and extrinsic motivations.

To deconstruct and understand the components of regulations, this paper uses the institutional grammar tool (IGT), initially formulated by Crawford and Ostrom (1995) and later revised by Basurto et al. (2010) and Siddiki et al. (2011). The IGT provides the means to partition the content of regulations into single statements or directives and, then, to identify the major constitutive components of these statements. These components can then be analyzed and configured to depict the behaviors that are required, permitted, and forbidden for actors under different contexts. Most importantly, regulatory deconstruction, guided by the IGT, helps isolate the particular components within regulations that can then be linked to compliant and noncompliant behaviors. For example, in one situation, noncompliance of a required behavior might result from the regulations not specifying the appropriate condition (time and place). In another situation, noncompliance might result from the target population interpreting the obligation as something permitted rather than required. Both situations of noncompliance necessitate a detailed understanding of regulatory design in addition to the perceptions and interpretations of actors in the regulatory system.

Compliance is examined in a case study of aquaculture regulations in Colorado, United States. Aquaculture is the practice of farming aquatic organisms (e.g. fish, shellfish, algae) (USGS 1996) for food markets, for restocking lakes and rivers, and for ornamental purposes (e.g. aquariums). The aquaculture industry is regulated throughout its life cycle: siting the aquaculture facility, obtaining water rights, acquiring effluent permits, assessing species health, acquiring feed, and transporting the product to its final destination (Ackefors et al. 1994). In the diversification and growth of global food systems, aquaculture is one of the fastest growing industries worldwide (Naylor et al. 2001). Aquaculture regulation is also understudied with most research to date in the US commenting on the cacophony of federal and state regulations (Firestone et al. 2004). To study regulatory compliance in the aquaculture industry, we selected Colorado as a case study because the industry is typical in size (USDA 2006) and because regulations that govern the industry are encompassed in just four different documents, making it feasible to code them in their entirety. Compliance with regulations in Colorado aquaculture is assessed through semi-structured interviews with regulators and regulatees. The paper finds that compliance varies across the interviewees and even within the same interviewee. Compliance levels are shaped by perceptions of the appropriateness of the regulations, participation in designing the regulations, feelings of guilt, and fear of social disapproval. 


\section{Introducing the institutional grammar tool}

Using the logic of the institutional analysis and development (IAD) framework (Ostrom 1990), Crawford and Ostrom (1995) attempted to unify the different interpretations of institutions as well as to offer an "institutional grammar" to understand institutional content. The institutional grammar provided a general approach for deconstructing the components of formal institutions: for example, the target audiences, topical subjects, prescriptive operators, and sanctions included within formal institutions such as policies, laws, and regulations. Their approach was innovative but lacked specific instructions for putting the institutional grammar into practice. As a result, the institutional grammar was largely ignored for the better part of the last two decades.

Recent efforts by Basurto et al. (2010) and Siddiki et al. (2011) have transformed the institutional grammar into the institutional grammar tool (IGT). Using the IGT, one can deconstruct regulations to increasing specificity: first, by parsing the written policies into institutional statements; and, second, by parsing institutional statements into components.

Crawford and Ostrom define institutional statements as "a shared linguistic constraint or opportunity that prescribes, permits, or advises actions or outcomes for actors (both individual and corporate)" (Crawford \& Ostrom 1995, p. 583). Most often, but not always, institutional statements are single sentences within regulations. Institutional statements represent the individual regulatory directives that specify certain components: at a minimum, an actor, a specific activity, and the temporal, spatial, or procedural boundaries of the activity. Each of the following sentences is an example of an institutional statement that might be identified and isolated from a regulatory document:

Aquaculture producers must annually reapply for an aquaculture permit or face closure of their facility.

Aquaculture producers may not export any fish exhibiting clinical signs of a prohibited disease.

Aquaculture producers may import certain types of prohibited species for research or educational purposes provided that the appropriate permits are obtained.

Once the institutional statements within a given regulation are identified, the statements are further parsed into six components: (i) Attributes, or the agent(s) charged with performing a particular action; (ii) oBjects, the animate or inanimate part of the statement that is the receiver of an action; (iii) Deontics, the prescriptive operator that specifies whether an action is required, allowed, or forbidden; (iv) aIms, or the action itself; (v) Conditions, which specify the spatial, temporal, and/or procedural boundaries in which the action in question is to be performed; and (vi) Or elses, the punitive sanctions associated with not performing an action as prescribed. ${ }^{1}$ Not all components must be present within any given institutional statement. At a minimum, institutional statements must contain three components: Attribute, aIm, and Condition. Table 1 provides an example of an institutional statement coded using the IGT, along with definitions of each component.

Recent applications of the IGT have sought to establish reliable coding guidelines, clarify the conceptual definitions of individual components, and provide insight regarding its practical and theoretical utility (Speer 2008; Basurto et al. 2010; Schlüter \& Theesfeld 2010; Siddiki et al. 2011). For example, Basurto et al. (2010) and Siddiki et al. (2011) 
Table 1 Example coding of an institutional statement: Facility owners shall annually submit a permit renewal application or pay a fine

\begin{tabular}{|c|c|c|}
\hline $\begin{array}{l}\text { Component } \\
\text { [ABDICO] }\end{array}$ & Component definition & Coding of example statement \\
\hline Attribute & $\begin{array}{l}\text { Agents charged with performing a particular } \\
\text { action }\end{array}$ & Facility owners \\
\hline oBject & $\begin{array}{l}\text { Animate or inanimate part of the statement } \\
\text { that is the receiver of an action }\end{array}$ & A permit renewal application \\
\hline Deontic & $\begin{array}{l}\text { Prescriptive operator that specifies whether } \\
\text { an action is required, allowed, or forbidden }\end{array}$ & Shall \\
\hline $\mathrm{aIm}$ & Action & Submit \\
\hline Condition & $\begin{array}{l}\text { Spatial, temporal, and/or procedural } \\
\text { boundaries in which an action is to be } \\
\text { performed }\end{array}$ & Annually \\
\hline Or else & $\begin{array}{l}\text { Punitive sanction associated with not } \\
\text { performing an action as prescribed }\end{array}$ & Or pay a fine \\
\hline
\end{tabular}

explored the utility of the IGT in comprehensively identifying the array of opportunities and constraints available to policy actors in various action situations, demonstrated how actors are linked across levels of analysis, and uncovered how the different components of institutional statements interact to animate the behavior of policy actors. Finally, seeking to demonstrate its versatility, Siddiki et al. (2011) described the tool's methodological applicability to understand the role of policy designs and the actors described within them in communities.

\section{Influencing regulatory compliance}

Two general categories of interdependent factors are examined for influencing individuals' compliance with regulations: regulatory design factors and intrinsic and extrinsic motivations.

\subsection{Regulatory design factors}

One important factor concerning the design of regulations is examining whether the scope of regulations is perceived as accurately reflecting the array of day-to-day activities of the individuals mentioned in the documents, including regulatees and regulatory officials. That is, are regulations relevant and appropriate to individuals mentioned therein? When the regulations are not perceived as appropriate, regulators and regulatees may question the legitimacy of the regulations and choose not to comply (Bardach \& Kagan 1982; Levi 1988; Ostrom 1990; May 2005, p. 321).

Another factor that has been demonstrated to influence the degree of relevance and applicability of regulations is participation in designing the regulations by those most likely affected by them (Ostrom 1990, 2005). Ostrom (1990) repeatedly demonstrated in her study of institutional design principles for effective common pool resource governance, that institutions are more likely to be representative of the realities of those affected by them when the latter have had the opportunity to participate in the institu- 
tional design process. ${ }^{2}$ A natural presumption is that locally tailored institutions will likely be more effective in fostering compliance.

In sum, we operationalize and measure the two regulatory design factors as the extent of perceived regulatory appropriateness and reported levels of participation in regulatory design.

\subsection{Intrinsic and extrinsic motivations}

Individuals are embedded in institutional, community, and physical/geographic contexts that may apply pressure to conform toward compliance or non-compliance of regulations. When making decisions, it is assumed that individuals consider such complementary or contradictory pressures to ascertain a course of action. Complicating this process, individuals' information is imperfect, as is their decision-making calculus; that is, they are boundedly rational (Simon 1985).

Taking all the above into account, we focus on three externally and internally derived motivations that shape individuals' compliance with regulations: fear of monetary sanctioning, fear of social disapproval, and feelings of personal guilt. Fear or monetary sanctioning and fear of social disapproval are both characterized as extrinsic motivations and feelings of guilt are characterized as an intrinsic motivation. A fear of monetary sanctions relates to the sanctions prescribed in regulations for non-compliance whereas fear of social disapproval relates to reputational concerns among fellow community members. ${ }^{3}$ Studies of individual decision making behavior have found, inter alia, the following factors to be influential in relation to these intrinsic and extrinsic motivations: (i) involvement of community members in labor unions (Offe \& Wisenthal 1980); (ii) change in resource availability with use (Hirschman 1985; Olson 1991; Mansbridge 1994); (iii) involvement of community members in rule development (Frey 1994); and (iv) perceived legitimacy of rules (Ostrom 2005). For the purposes of this study, such variables are characterized as "contingent variables," meaning that the extent to which intrinsic and extrinsic motivations will be expressed in individuals' decision making is contingent upon a variety of community-based, bio-physical, and higher-level institutional variables, plus individual situational and endogenous norms (e.g. moral and cognitive bias). Individual situational factors are those that relate to individuals' personal circumstances, such as the length of time they have been employed in a particular occupation or lived in a certain location. For example, the degree to which the fear of social disapproval (primary compliance motivation) is a motivating (or demotivating) factor for an individual to comply with institutional directives may be tempered by the length of time s/he has resided within a particular community (contingent motivation).

This paper seeks to contribute to the understanding of compliance by analyzing regulatory components in conjunction with regulatory design factors as well as intrinsic and extrinsic motivations. We offer four specific research questions in an attempt to gain a better understanding of the degree of regulatory compliance:

$\mathrm{RQ}_{1}$ : To what extent are the descriptions of situations described in regulations reported by interviewees as representing their day-to-day activities?

$\mathrm{RQ}_{2}$ : To what extent do perceived regulatory appropriateness and participation in designing regulations influence individuals' compliance with regulations?

$\mathrm{RQ}_{3}$ : To what extent do fear of monetary sanctioning, fear of social disapproval, and/or feelings of personal guilt influence individual decisions to comply with regulations? 
$\mathrm{RQ}_{4}$ : Which contingent factors are most influential in shaping the expression of compliance motivations?

\section{Methods of data collection and analysis}

To respond to the posited research questions, we applied two distinct but related methodologies. First, we identified and coded the regulations to analyze the prescribed set of written required, allowable, and forbidden actions. Second, we used a dual interview approach applying a semi-structured interview protocol and related Q-Sort technique to assess the degree of congruency between prescribed and actual behavior and to uncover how actors weigh compliance motivations when deciding whether to adhere to prescriptions within the regulations.

\subsection{Identifying and coding Colorado aquaculture regulations}

The two primary agencies charged with the regulation of aquaculture in Colorado State are the Colorado Department of Agriculture (CDoA) and the Colorado Division of Wildlife (CDoW). The CDoA is responsible for permitting procedures relating to aquaculture and has two complementary legislative documents: the Colorado Aquaculture Act (CAA) Statute (CDoA 1991) and the Rules Pertaining to the Administration and Enforcement of the Colorado Aquaculture Act (CDoA 1992). Together, these two documents detail the structure and responsibilities of the Aquaculture Board, specify the fee structure for different types of aquaculture permits, and provide administrative instructions for aquaculture producers; for example, these documents include directives pertaining to record keeping of aquaculture acquisitions, destruction of aquatic organisms, and the sale of aquaculture products. The CDoW deals with matters of fish health and is charged with implementing two legislative documents that deal directly with aquaculture. The first, Article VII of the Chapter 00 - General Provisions (CDoW 1991), specifies prescribed fish health testing, responsibilities of the State Fish Health Pathologist, and disinfection and quarantine procedures. The second, Section 33-5.5-101 of Title 33 of the Wildlife and Parks and Regulations Rules, outlines the responsibilities of the Fish Health Board as they pertain to aquaculture. ${ }^{4}$

We applied the IGT to code the four regulatory documents governing aquaculture practice in the State of Colorado. Across the four regulations 346 statements were identified. One member of the research team coded each of the four regulations in its entirety. A second member of the research team coded 35 statements from the Colorado Aquaculture Act Administration and Enforcement Rules, comprising approximately ten percent of the total statements across all documents, as a test for inter-coder reliability. Inter-coder reliability results were calculated based on agreement per statement component. The following agreement rates were observed between the two coders on each component: Attributes (86\%), oBject (86\%), Deontic (97\%), aIm (94\%), Condition $(80 \%)$, and Or else (100\%).

To summarize the data, we conducted a basic frequency count for the four regulations to determine the total number of statements within each document (Table 2). We also categorized these statements by their components, that is, whether they constituted strategies, norms, or rules. According to the IGT, a strategy is composed by an AttributeaIm-Condition (AIC) or Attribute-Object-aIm-Condition (ABIC) statements. A norm is made of Attribute-Deontic-aIm-Condition (ADIC) or Attribute-Object-DeonticaIm-Condition (ABDIC) statements. And a rule is constituted by Attribute-Deontic- 


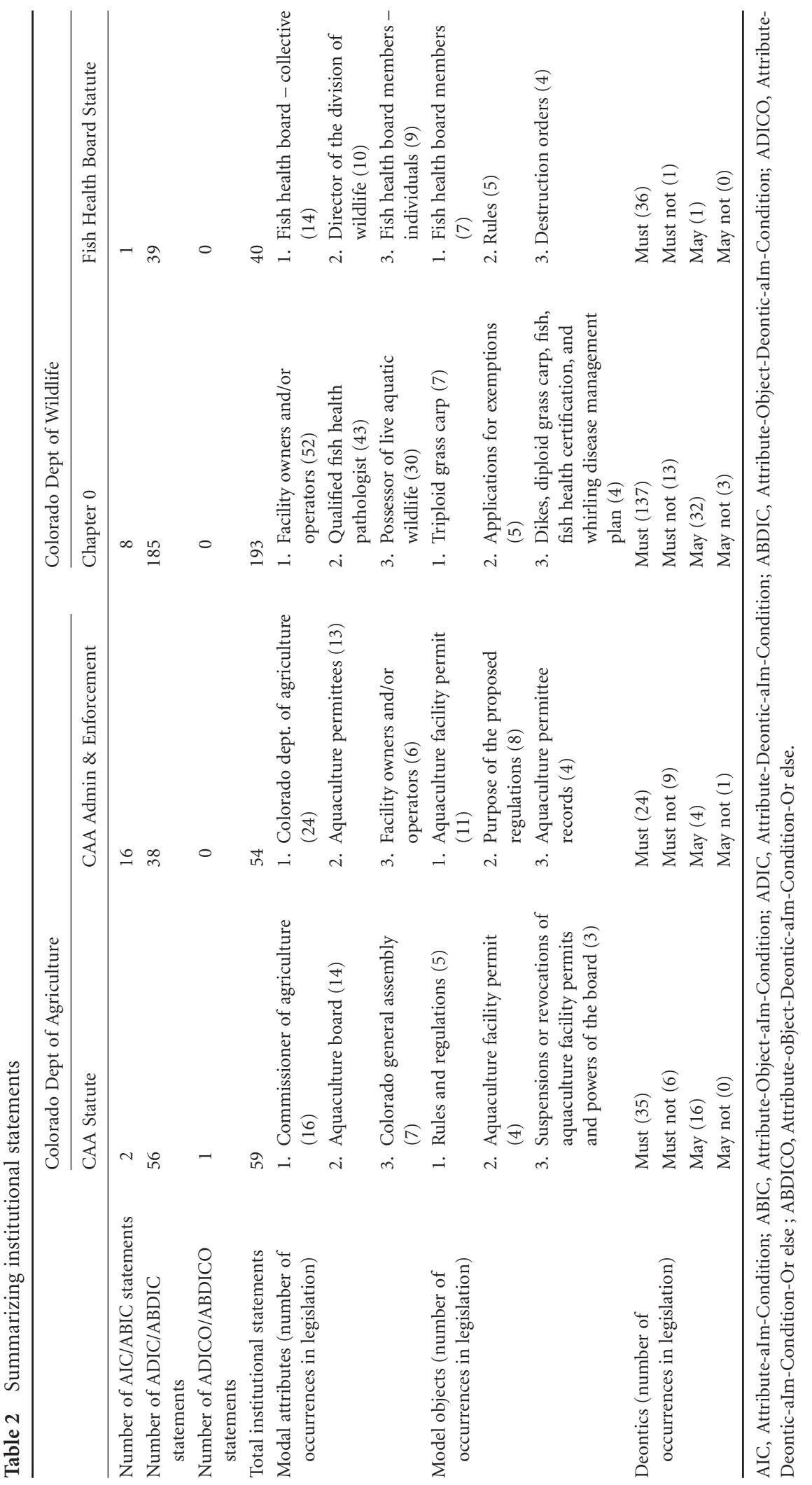


aIm-Condition-Or else (ADICO) or Attribute-oBject-Deontic-aIm-Condition-Or else (ABDICO) statements. For clarity purposes in this paper, we avoided using the terms of strategies, norms, and rules to differentiate between institutional statements because all statements in formal institutions - coded as part of this project - are regulations, which could be interpreted as rules because there is an implicit "Or else" present. We considered the documentation of the relative frequency of each categorization (i.e. AIC/ABIC, ADIC/ $\mathrm{ABDIC}, \mathrm{ADICO} / \mathrm{ABDICO}$ statements) as useful to provide better understanding of the content of regulations. Completing the descriptive summary of the regulations is a frequency count to determine the actual Attributes, oBjects, and Deontics most frequently occurring within each. A simplified descriptive summary of Conditions is not feasible in the current paper given the range of specific Conditions associated with regulatory directives. Very few statements in the regulations coded for this exercise contained Or elses and, thus, a descriptive summary for this code is also not provided in Table 2.

In summarizing the Attributes, oBjects, and Deontics within each of the regulations in this manner, we explored how the components from institutional statements were intended to cumulatively structure individuals' behavior (Ostrom 2005, p. 175). Additionally, we identified the modal Attributes (that is, the category of people most commonly listed in the regulations) and various characteristics and activities regarding them. Each of the modal Attributes from the four regulations was linked with the actions in the aIm, oBjects, related Deontics, and sometimes Conditions. Through this exercise, we were able to gain a better understanding of how the different Attributes present within the regulations were linked via four Deontics (must, must not, may, may not) to certain activities. Table 3 provides examples of statements linked with three different types of Attributes - Fish Health Board, Colorado Department of Agriculture, and Facility Owners and Operators - and the Deontics assigned to these statements.

For a more complete depiction, Figure 1 shows each of the statements linked with a particular Attribute from the regulations - the Fish Health Board.

In addition to allowing one to start understanding the activities associated with particular actors, a mapping of institutional statements was also necessary as it served as the basis for the second round of data collection via formal interviews. For example, the modal Attributes formed the sample pool for the interviews. Additionally, individual institutional statements were used as the preselected statements that interviewees would be asked to sort during the Q-Sort exercise.

\subsection{Interviews}

The sample of interview participants included modal actors from the four regulations coded for the exercise, including four facility owners and/or operators (i.e. aquaculture producers), the Colorado State Fish Health Pathologist, one representative from the Colorado Department of Agriculture, one member of the Colorado Aquaculture Board, and one member of the Fish Health Board. Both the member of the Colorado Aquaculture Board and the Fish Health Board were also facility owners and/or operators. A total of seven formal, semi-structured interviews were conducted. Some of the interviewees have multiple roles in the aquaculture community (eg. Fish Health Board member and facility owner) and this was reflected in their responses to interview questions in which they provided answers from the perspective of each of the positions held. 


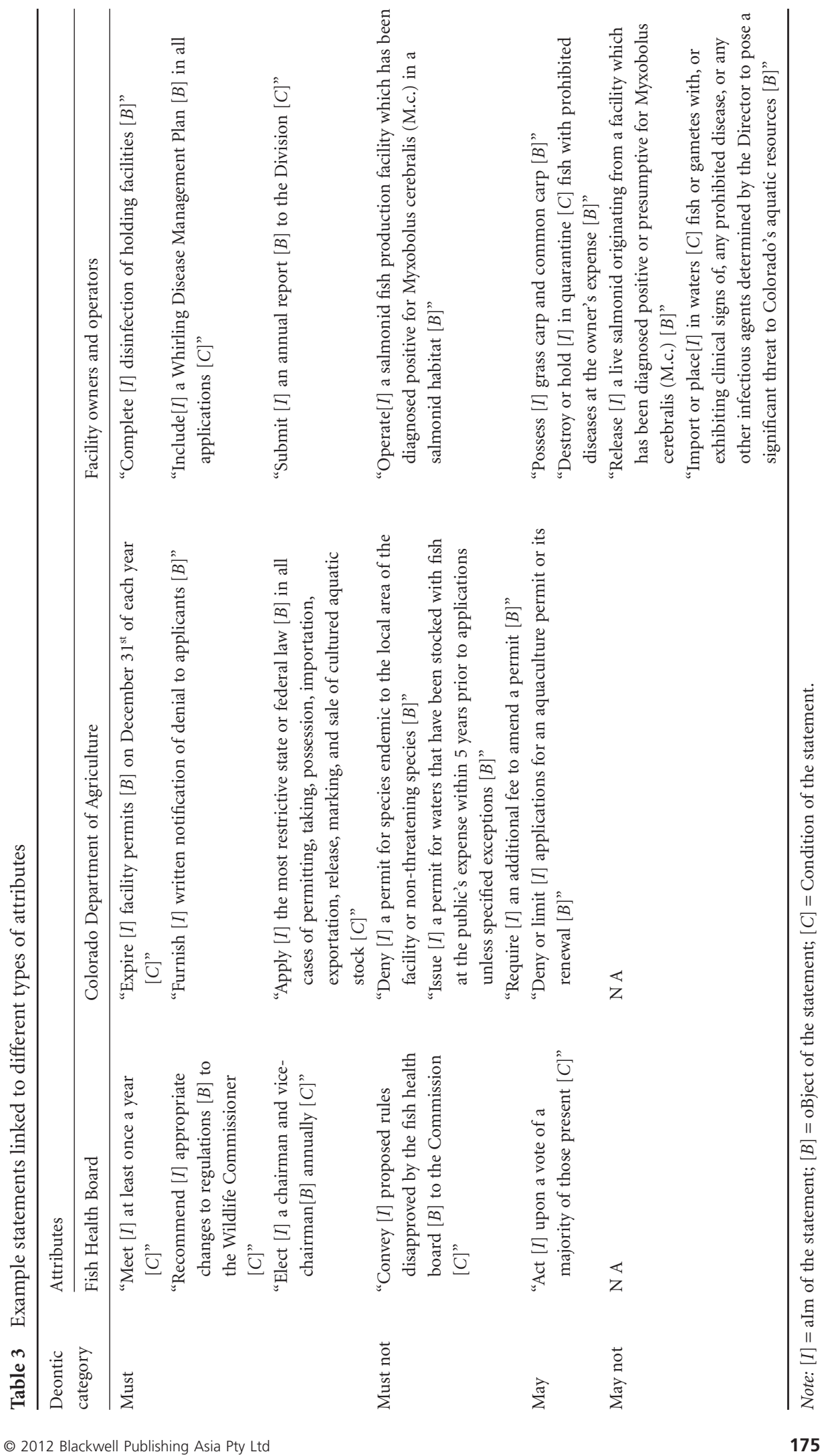




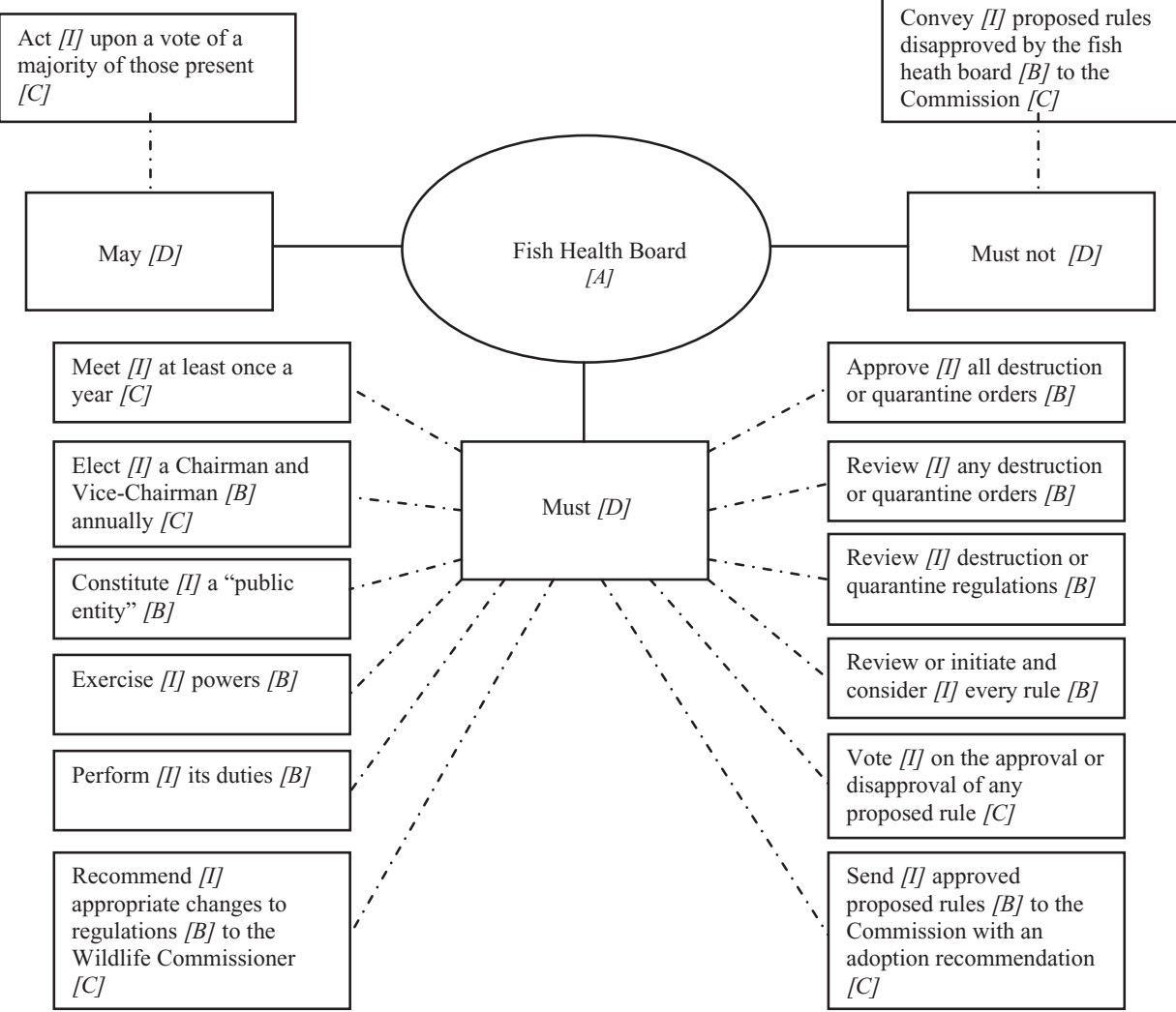

Figure 1 Attribute cluster analysis: Fish Health Board.

Note: $[A]=$ Attribute; $[B]=\operatorname{oBject} ;[D]=$ Deontic; $[I]=\mathrm{aIm} ;[C]=$ Condition of the statement.

The interviews consisted of two parts. In the first part, interviewees were asked a series of questions based on a formal, structured interview protocol. In the second part, interviewees were asked to participate in a Q-Sort exercise. The Q-Sort is a methodological technique that allows study participants to subjectively sort a preselected set of statements into a set of categories designated by the researcher (McKeown \& Thomas 1988). Sample statements can be chosen following an unstructured or structured approach. In the latter, the researcher chooses the statements that will be sorted based upon prior collected information, such as through preliminary interviews or from the examination of existing documents.

\section{Results}

\subsection{Interview part 1: Protocol-based interview - examining contextual appropriateness of regulations}

Questions asked during interviews were directly related to the interviewee's role and responsibilities as presented in the regulations. Questions were structured around statement components from the IGT (Attributes, oBjects, Deontics, etc.) and catered for the particular position/role of the interviewee in the aquaculture community as prescribed in the coded regulation. A list of grammar-related interview questions can be found in the Appendix. 
The formal interview protocol included a number of questions relating to the history and context of the regulations, regulatory compliance, and regulatory effectiveness. However, analysis of interview data focused primarily on questions related to the grammar components to understand the utility and theoretical relevance of parsing institutional statements by Attributes, oBjects, Deontics, aIms, Conditions, and Or elses. With respect to Attributes (performers of actions in the regulations), five out of the seven interviewees stated that they represented the appropriate target audience for the respective regulations, including four facility owners, one of whom was also a member of the Fish Health Board, and the State Fish Health Pathologist. In most cases these individuals stated that regulations appropriately targeted them as being important in the functioning of the aquaculture industry in Colorado. Level of influence within the aquaculture community was also cited as a reason for the appearance of certain actors in the regulations. For example, the member of the Fish Health Board, the entity charged with approving most mandates within aquaculture regulations in Colorado, stated that the Board was very influential in shaping the aquaculture industry in the State.

Those who stated that they were not the appropriate target audience of the regulation, including a representative from the State Department of Agriculture and a member of the Colorado Aquaculture Board, stated that their frequent mention in the regulations overstated their influence in the management of the aquaculture industry. With respect to the Colorado Aquaculture Board, the member stated that the Board was only called upon under certain circumstances to perform the activities described in the regulations, while the regulations make it appear that the Board was performing these activities on a regular basis. The Colorado Department of Agriculture representative described how many of the regulatory responsibilities assigned to it were performed jointly by the Department and the Colorado Division of Wildlife, even though the regulations suggested the Colorado Department of Agriculture was the sole actor.

Regarding the oBject questions (questions related to the activities described in the regulations vis-à-vis Attributes), we were interested in knowing if the number of activities prescribed to a particular actor/entity provided an indication regarding the scope of aquaculture activities s/he/it was regularly involved in, as well as the level of influence of the Attribute. For example, if an individual was associated with a larger number of activities, does this mean that his/her scope of activities and/or influence was commensurately greater? Of the six interviewees that responded to this question, three responded that the regulations accurately portrayed the scope of their activities relating to aquaculture, while three said the regulations did not. Of those who responded positively, two remarked that the nature of their work in aquaculture was highly specialized and, thus, they were related to relatively few activities that were substantively narrow. One interviewee commented that regulations defined the scope of activities as they related to particular actors and, thus, consistency was observed between prescribed and actual activities. Of those who responded negatively, one interviewee stated that regulations provided an inaccurate representation regarding his role in the aquaculture community, which had waned in recent years. Another noted that, while the group he represented was not associated with many activities in the regulations, the content of the relatively few activities mentioning his group reflected the group's broad-reaching influence. In other words, one must not only consider the number of activities associated with an actor mentioned in the regulations, but also the types and implications of the activities. Some types of activities were more significant in terms of the level of impact than others. The 
third interviewee, a facility owner, indicated that Conditions dictated whether or not a particular activity within the regulation was relevant to a particular person. In other words, there were a wide variety of activities described in the regulations in relation to facility owners, not all of which were applicable to everyone. Applicability was based on Conditions that specify to whom certain activities apply and under which circumstances. For example, certain fish health testing requirements may or may not have been applicable to a particular facility owner depending on whether or not his/her facility had ever tested positive for certain types of diseases in the past.

Regarding the aIm/Deontic question (questions that described activities as well as whether such activities were required, forbidden, or permitted), of the five interviewees that responded to this question, three stated that they interpreted prescriptive operators very literally and two stated that they interpreted the different prescriptive operators with some degree of leniency. One of the latter interviewees, charged with enforcing regulations, elaborated that his interpretation of the regulations was based largely on a caseby-case base determination of the perceived appropriateness of a prescription in relation to a farmer's activities. He then stated that, oftentimes, non-compliance with regulations had minor or negligible implications.

For the Condition question (questions that described when and how activities were to be conducted), all five interviewees expressed that the Conditions were extremely important in determining their compliance levels. The State Fish Health Pathologist, for example, mentioned that detailed conditions were written to provide clarity regarding what was required, allowed, and forbidden when conducting fish health testing and inspections. For example, the regulations specified that inspections must be conducted annually and that they must be conducted in accordance with guidelines specified by the US Fish and Wildlife Service and the American Fisheries Society. The Fish Health Board member stated that Conditions were a major consideration when hearing cases of noncompliance to determine a violator's sanction. He further stated that Conditions largely shaped his interpretation of the regulatory Deontics and associated phrases. For example, a "must" was really only a "must" under certain conditions, and the same goes for other types of Deontics. For instance, in the following example, facility owners were not permitted to operate a facility that had tested positive for the fish disease Myxobolus cerebralis (M.c.) unless certain exemptions had been granted to him/her by the relevant authorities: "No person shall [i.e. a person shall not] operate a salmonid fish production facility which has been diagnosed positive for Myxobolus cerebralis in salmonid habitat unless an exemption allowing such operation has been granted by the Director after consultation with the Fish Health Board" (CDoW 2009). The presence of such an important exemption would temper how a facility owner interpreted the "must not" Deontic included within this statement. Additionally, one administrative representative commented that many times the Conditions upon which decisions were made were not formally written in legislation but were rather informally considered based on particular circumstances. He stated that this was particularly true for cases that were viewed as less serious. Where cases of non-compliance were more serious, a stricter adherence to formally stated Conditions was used.

Across the four regulations, very few statements contained Or else components (i.e. sanctions). Interviewees were asked to provide their opinion on this finding. Of the seven individuals that responded to this question, three stated that this was due to a lack of enforcement capacity by regulating agencies. Two interviewees stated that, as those indi- 
viduals responsible for enforcing rules, they preferred to deal with non-compliance issues on a case-by-case basis rather than imposing blanket penalties within regulations. Both individuals stated that the observed leniency largely reflected the desire to maintain harmonious relations between regulating agencies and members of the industry.

\subsection{Interview part 2: Q-sort - examining compliance}

For the second part of the interviews, we conducted a Q-Sort exercise with interview participants. Five individuals participated in the Q-Sort exercise to conduct a total of six sorts. One interviewee, who held dual positions in the aquaculture community, conducted two sorts and the remaining participants conducted one sort each.

For our analysis, we used a modified, structured Q-Sort in which each study participant was given a set of cards containing statements that describe activities that relate to his/her position in relation to aquaculture as prescribed in one of the four regulatory documents analyzed in this study. The participant was asked if s/he "must," "must not," "may," or "may not" perform the activity described on the card based on adopted practices. For example, facility owners were given a card containing the following statement with the "may" Deontic removed: "Destroy or hold in quarantine fish with prohibited diseases at the owner's expense." The interviewee was then asked to place this statement into the Deontic category which best reflects how s/he performs this activity in his/her own operation; that is, whether his/her actual activities reflects his/her interpretation of the activities being specified on this card as being required, allowed, forbidden, and so on. We chose to use the Q-Sort technique in our interviews as we felt it would allow us to capture the daily behaviors exhibited by interviewees, which we could then formally and systematically compare to the formal institutions. Once the sorting exercise was completed, the researcher asked the participant to explain the placement of statements. Follow-up questions were structured around pro-factual and counterfactual prompts as well as probes relating to the interviewees' motivations in performing/not performing prescribed activities. Additionally, interviewees were asked to articulate how they interpreted and weighted different prescriptive operators.

Q-Sort data were first analyzed by calculating the percent alignment between the content of actual regulatory statements and interviewees' description of their activities as reflected in their placement of Q-card statements into the four different Deontic categories. The results from this exercise are provided in Table 4. For each attribute, the table displays the total number of "must," "must not," "may," and "may not" statements in respective regulations, the number of statements placed in each of the Deontic categories by the participant, the number of statements correctly identified, and the percent agreement between the placement of the Deontic by the participant and the actual Deontic in the regulation.

The average percentage agreement across the Deontic categories differed markedly across the different Attributes, ranging from 17 percent to 66 percent. Agreement tended to be higher for "must" Deontics, implying that interviewees were most knowledgeable about activities they were required to perform in their actual aquaculture practices. This finding is an indication that, while the average agreement across Deontic categories was relatively low in some cases, instances of non-compliance were not likely characteristic of gross negligence. Further, many individuals may reference documents for clarification on activities allowed and forbidden before taking action in a real situation, while the Q-Sort exercise relies to some extent on their recall of regulations. 


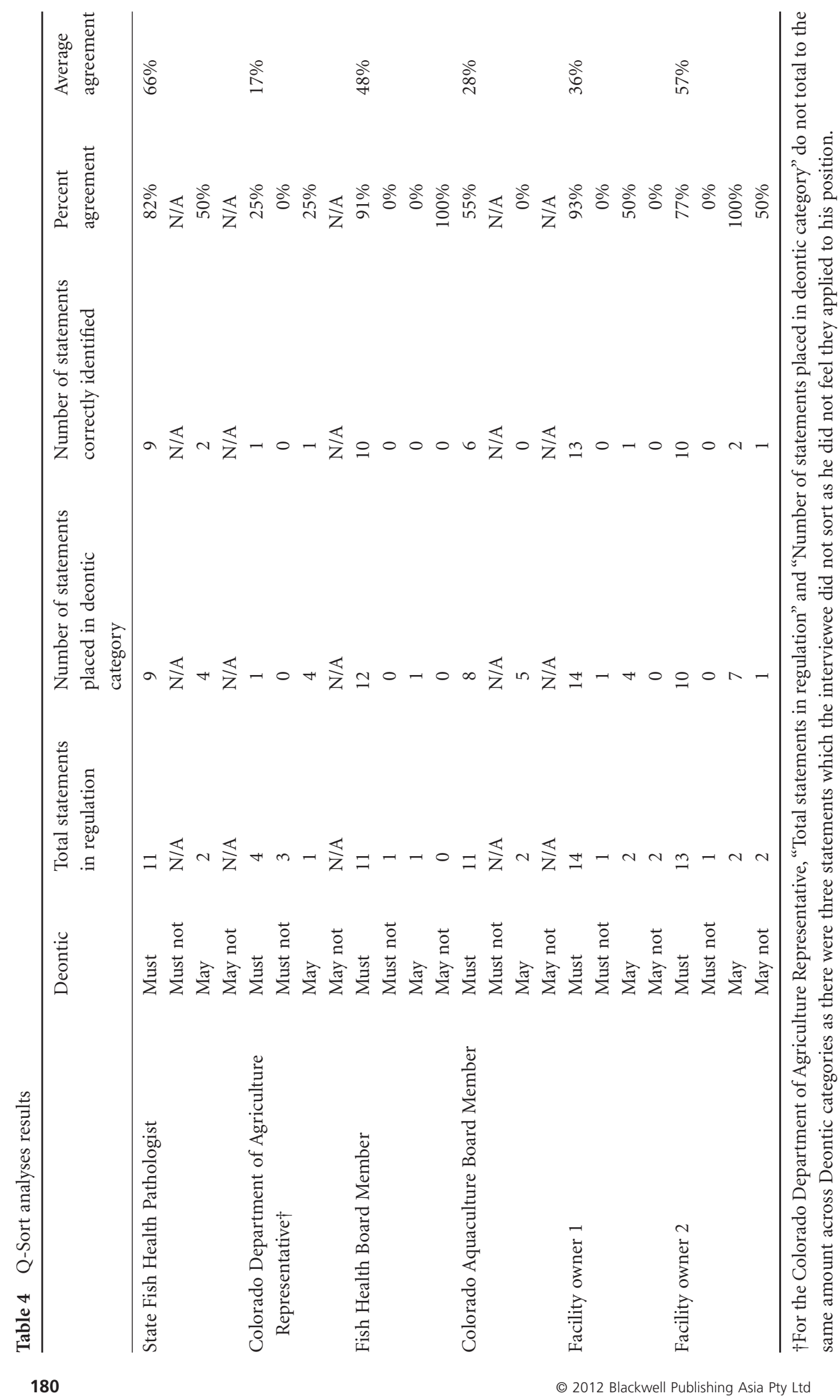


An initial assessment of the relationship between perceived contextual appropriateness of regulations and compliance indicates the highest agreement among interviewees who stated that regulations accurately represent the scope of activities they were regularly engaged in. These individuals include the State Fish Health Pathologist, member of the Fish Health Board, and a facility owner. Further, each of these individuals also reportedly participated in the development of regulations at one point in time.

Next, interviewees' responses regarding the motivations that influence their choices relating to regulatory compliance were analyzed. Of the seven interviewees who participated in the study, five responded to this set of questions. The responses given by interviewees reveal interesting nuances regarding both the calculus of compliance motivations and the contingent factors that influence their expression. In the majority of the cases, endogenous norms were the most prevalent contingent factor emerging from a community-derived sense of reciprocity and/or responsibility.

Two of the interviewees stated that feelings of guilt were the primary motivator influencing their decisions regarding compliance with regulations and one interviewee stated such feelings were the second most influential factor. One of the interviewees was the member of the Fish Health Board, the entity charged with reviewing any rule that was to be incorporated into the aquaculture regulations, and also a facility owner. According to this interviewee, feelings of guilt were the primary motivator for his literal interpretation of Deontics and this was grounded in his desire to promote a fair and equitable regulatory process, both as someone involved in the development of the regulations, as well as someone whose activities are governed by them. Another of these interviewees was the State Fish Health Pathologist. In this interviewee's case, feelings of guilt emerged from implementing a prescriptive required by regulation that was not grounded in sound scientific evidence. That is, implementing a prescriptive that he felt could be of detriment to industry. In such cases, the interviewee stated that he would contact the authorities to pursue amendment to the rule.

One of the interviewees, responsible for the administrative aspects of aquaculture development in the State, indicated that social disapproval was the strongest factor in his decision-making relating to regulations, followed shortly by feelings of guilt. $\mathrm{He}$ further indicated that his fear of social disapproval from industry members in particular, for whom he had a lot of respect, led him to relax his interpretation of "must" Deontics. He stated that he had little desire to hurt aquaculture farmers who had good intentions but failed to meet requirements occasionally; this goes for cases when the non-compliance had harmless implications. He stated that this was the position adopted by the regulating agency of which he was an employee and thus the culture of the agency toward industry was marked by a desire to maintain harmonious relations.

Two of the interviewees that responded to these questions did not explicitly state which compliance motivations were most influential in guiding their decisions. Instead, however, they elaborated on the contingent factors upon which their decisions were based. For example, one facility owner, who expressed a strong internal norm to follow regulations as closely as possible, indicated that he felt accountable to government agencies and fellow industry members to set a good example as a person of authority in the aquaculture community. He further elaborated that while the duty to serve as a role model in the community was not a requisite of his professional position, it was part of his personality that he should take this responsibility upon himself. Another interviewee 
stated that facility owners in general have expressed a norm to adhere to regulatory mandates as a part of their duty to the law.

\section{Discussion}

Our study was guided by the need to better understand how a deconstruction of regulatory design can be used to inform our understanding of regulatory compliance and compliance motivations. In response to this need, we posed four specific research questions and found the following results:

\subsection{To what extent are the descriptions of situations described in regulations reported by interviewees as representing their day-to-day activities?}

Results suggest variation in alignment between prescribed and actual activities, or compliance. We find some respondents reporting strong alignment between their daily behaviors and the regulations and with others we found weak alignment. The results indicate that compliance was most often observed for "must" statements prescribing required activities. The degree of alignment on these "must" directives was influenced by perceived scope appropriateness and participation in designing the regulations.

Underscored by our empirical results is that the extent of compliance is fundamentally an empirical question and subsystem-wide claims should not be made without a systematic investigation representing the breadth and depth of actors. Indeed, the results show that even for the same actor or groups of actors there might simultaneously be both strong and weak levels of compliance depending on the specific institutional statement examined.

\subsection{To what extent does perceived regulatory appropriateness and participation in designing regulations influence individuals' compliance with regulations?}

Our initial assessment of the relationship between regulatory design factors and compliance show that the highest degree of alignment between prescribed and actual behavior was observed when interviewees reported that regulations accurately reflect their regular scope of activities. Furthermore, these individuals, at some point in time, have participated in the development of regulations. Most disagreement between prescribed and actual behaviors was observed when interviewees stated that regulations did not accurately represent their role in the aquaculture community or where the interviewee stated that prescriptive operators were purposefully interpreted with a degree of leniency.

Regarding institutional scope, one interviewee described how the institutions can be constitutive in nature; that is, they created activities for constituents and also defined whether these activities (i) were allowed, required, or forbidden; (ii) were bounded by temporal, spatial, and procedural conditions; and (iii) were associated with specified sanctions for non-compliance. For example, aquaculture regulations formed the administrative rules for permitting requirements and defined the ways in which aquaculture producers must meet such requirements. The interviewee, who commented on this quality of aquaculture regulations, described how regulations accurately defined the scope of activities as they related to particular actors. Thus, consistency is observed between prescribed and actual behavior.

Our empirical approach and data collection also suggest that partitioning institutional statements along grammar components has theoretical and practical relevancy 
when seeking to understand the relationship between prescribed and actual activities of community members. For example, in most cases, modal Attributes in the regulations were the primary actors involved with the actual regulated activity, and oBjects tended to accurately reflect the scope of their actual activities and/or influence. Understanding the content of regulations or formal institutions using the IGT also can allow the researcher to organize and guide the development of a rigorous questionnaire to learn about how actual behavior compares with what is prescribed.

\subsection{To what extent do fear of monetary sanctioning, fear of social disapproval, and/or feelings of personal guilt influence individual decisions to comply with regulations?}

The results from our preliminary analysis suggest that feelings of personal guilt and fear of social disapproval, together, might be more influential in shaping individuals' decision-making regarding compliance with regulations than fear of monetary sanctioning. These assertions must be interpreted with caution given the small sample of interview participants and should be verified through an experimental research design. However, based on this study's findings, we can tentatively conclude that, as expected, individual and community based characteristics play a significant role in shaping individuals' decision-making behavior alongside regulations. The extent to which feelings of personal guilt matter will likely be contextually based, contingent upon community, biophysical, political/regulatory, and endogenous characteristics. For example, feelings of guilt are possibly more important than monetary sanctions for compliance when noncompliance has the potential to affect negatively social relations and the monetary sanctions are relatively trivial and rarely enforced. In other words, the expression of these is contingent upon a variety of factors, as demonstrated by interview responses. Such contingent factors must be explored to more fully understand how individuals internalize and express different compliance motivations.

\subsection{Which contingent factors are most influential in shaping the expression of compliance motivations?}

The data collected from the interviewees suggests that compliance motivations depend partly upon contingent factors. Responses given by interviewees revealed that, in the majority of the cases, endogenous norms were the most prevalent contingent factor, emerging from community-derived norms of reciprocity and/or responsibility. For example, when explaining their motivations to comply with regulations, interviewees commented on personal feelings of responsibility to the industry, a desire to maintain harmonious relations with other industry members, a desire to maintain a fair and equitable regulatory process, and a commitment to regulations that promote scientifically sound practices within the aquaculture industry. One interpretation of this finding suggests that interviewees' motivations were rooted in endogenous norms to promote reciprocity and cohesion among members of the aquaculture community. Beyond the four research questions, this study finds interdependencies among the components within a particular institutional statement. For instance, we find a strong link between Deontics (must, must not, may) and Conditions (describing when and how an action is to be conducted). Several interviewees indicated that their interpretation of Deontics was contingent on Conditions. For example, only observing Deontics in the regulations would have required certain types of fish health testing by all aquaculturists. However, 
associated Conditions indicated that several fish health tests were required only by facilities that have tested positive for a particular disease within a given time period.

\section{Conclusions}

The politics of the distribution of burdens and benefits and the very style of governance in any society is largely determined by the design of constitutions, laws, policies, and regulations. This paper provides an approach with the institutional grammar tool (IGT) for deconstructing the components of regulations and then to investigate the factors associated with regulatory compliance. The findings are fivefold:

1 Variation within and across actors in their reported level of regulatory compliance. To assert that a community is in compliance or that even a single individual is compliant might be a useful heuristic, but most likely a false one. Based on our small sample of respondents, there were differences across interviewees in their reported congruence in placing the correct Deontic (e.g. a must or a may) with the appropriate institutional statement. Additionally, a single interviewee might report compliance with some institutional statements and non-compliance with others. The interplay, thus, between regulatory documents and actual behavior is probably more complex than previously articulated, particularly if we start focusing on the minute details of regulations.

2 Perceived appropriateness of regulatory scope seems to affect compliance and the relevance of compliance. Scope is the extent which the regulations encompass the range of activities conducted by actors (regulators and regulatees) involved in the regulatory system. The results suggest that the scope of regulation determines the level of compliance and whether compliance matters at all. For example, one might find that a policy with ten institutional statements for actor A may encompass 90 percent of actor A's actual, daily activities making these ten institutional statements both a highly congruent and fairly complete match of actual behavior, whereas ten institutional statements for actor B may encompass only 10 percent of actor B's actual activities making these ten institutional statements a congruent yet incomplete representation of actual behavior. Thus, researchers should consider both scope and compliance when examining the relationship of regulatory components with behavior. The IGT is particularly useful in determining the scope of regulatory design. Through a systematic identification of aIms and oBjects, the analyst may gain a comprehensive understanding of the range of activities associated with different Attributes. The coded data then serve as a foundation upon which to assess perceived scope in relation to compliance.

3 Guilt and fear of social disapproval seem to be important factors for influencing compliance. Regulatory scholars have acknowledged the influence of social disapproval in positively affecting compliance, as found in this study (Braithwaite \& Makkai 1991; Sutinen \& Kuperan 1999; Hatcher et al. 2000). Hatcher et al. (2000), for example, found that social pressures served as an effective deterrent for non-compliance relating to catch quotas, or individual fishing quotas, in the United Kingdom. This study's findings with respect to social disapproval are also consistent with the logic of the Institutional Analysis and Development (IAD) framework, which emphasizes the role of individual and 
community-based influences in shaping compliance with institutional, or regulatory, directives (Ostrom 2005, pp. 26-27). Regulatory scholars have also studied the positive influence of guilt in relation to compliance (Grasmick \& Bursik 1990; Scholz and Pinney 1995), though much of the research on guilt has been conducted in laboratory settings (Freedman et al. 1967; Carlsmith \& Gross 1969). Isolating the influence of guilt in non-laboratory settings is certainly more challenging, but clearly an important endeavor in light of the findings of this and past regulatory studies.

4 The components of the IGT are interdependent. The interviews made clear that the relationships among components of the institutional statements are interdependent. For example, our prior expectation, perhaps naïve, was that a "must" Deontic represented required behavior independent of the Condition components of the statement. Instead, we found that the influence of the Deontic is interdependent with the Conditions. We postulate, for example, that strict temporal and process Conditions strengthen the "must" Deontic whereas lenient temporal and process Conditions weaken the "must" Deontic. Take an extreme example: requiring that an aquaculture producer must submit a particular permit but without specifying a strict deadline with a Condition severely weakens the likelihood of compliance because the aquaculture producer could choose to submit the permit tomorrow, next year, ten years from now, or - possibly through constant delays - never.

5 Contingent factors seem to condition the expression of compliance motivations. Contingent factors are the contextual forces that determine the relative weight of intrinsic and extrinsic motivations. The findings suggest that contingent factors based on endogenous norms to maintain reciprocity and cohesion among the aquaculture community strongly influence the expression of intrinsic and extrinsic motivations. The sample of members of the Colorado aquaculture community across professional positions exhibits a strong desire to maintain a fair and sympathetic process toward one another, which has notable implications for the management of the aquaculture industry in Colorado, and more broadly. First, maintaining a fair and sympathetic process shaped how individuals interpret regulations, particularly the Deontics (must, must not, may). For facility owners, this has often resulted in a more strict interpretation of Deontics, while for those enforcing regulations, this has led to a more relaxed interpretation. Second, maintaining a fair and sympathetic process has also influenced the design of regulations that govern the industry. Interviewees reported that regulations were purposefully non-stringent to allow for a higher degree of leniency in their interpretation and enforcement.

One of the major challenges in studying regulatory compliance is adequate sampling of a sizeable population of respondents to account for the individual, day-to-day behaviors of that population. This study involved a sample of the modal actors listed by the regulations but not an exhaustive portrayal of the entire population. Still, this population represents the major actor categories mentioned in the regulations and individuals actively involved in, and knowledgeable about, Colorado aquaculture. Such a sample limits the degree to which lessons can be drawn from the results but also represents good breadth considering its small number. Another challenge is ascertaining which types of intrinsic and extrinsic motivations, and the contingent factors upon which their expression is based, will be most influential in complying with regulations across different 
contexts. In order to address this challenge, the motivations explored in this study must be subjected to additional empirical testing across different regulatory contexts and, ideally, over time.

In examining regulatory compliance, this study addresses two challenges associated with the study of governance. First, it demonstrates how the IGT can be applied to develop a systematic understanding of the constitutive components of regulatory design. The effort helps develop a greater comprehension of the products of past politics and of future politics. Among the next steps are to take the components and analyze them comparatively and over time to describe institutional change. Second, this paper complementarily assesses the influence of variables relating to regulatory design and behavioral motivations relating to regulatees' individual and community contexts on compliance. Therefore, it serves as a solid foundation for further studies of regulatory compliance wherein it is presumed that compliance is affected by influences emerging from both realms.

\section{Acknowledgments}

The National Science Foundation supported this work under grant number 0913001. Any opinions, findings, and conclusions or recommendations expressed in this material are those of the author(s) and do not necessarily reflect the views of the National Science Foundation. We would like to thank David Levi-Faur and the anonymous reviewers whose constructive feedback significantly improved this paper. We would also like to recognize John Calanni for his assistance in coding the aquaculture policies and the interviewees for generously sharing their time and experiences with us.

\section{Notes}

1 The original grammar was abbreviated with the acronym ADICO (Crawford \& Ostrom 1995). The addition of the oBject added another letter ABDICO (Siddiki et al.2011). We capitalize the grammar components based on these letters to remind the reader that the words represent concepts in the IGT.

2 In the literature of the IAD framework, institutional design refers to the same statements and components described in this paper that operate in configuration in governing various action situations. The major difference is that this paper focuses upon regulations, a specific type of institutional design.

3 Crawford and Ostrom (1995) characterized these internally and externally derived motivations as "delta parameters," though herein they will be articulated more generally as intrinsic and extrinsic compliance motivations.

4 Interviews were conducted with two members of the aquaculture community to identify these four regulatory documents as the major policies governing aquaculturists in the State (see Section 5).

\section{References}

Ackefors H, Huner JV, Konikoff M (1994) Introduction to the General Principles of Aquaculture. The Haworth Press, Inc., New York, NY.

Bardach E, Kagan RA (1982) Going by the Book: The Problem of Regulatory Unreasonableness. Transaction Publishers, London.

Basurto X, Kingsley G, McQueen K, Smith M, Weible CM (2010) A Systematic Approach to Institutional Analysis: Applying Crawford and Ostom's Grammar. Political Research Quarterly $63,523-537$. 
Becker G (1968) Crime and Punishment: An Economic Approach. Journal of Political Economy 76, 169-217.

Braithwaite J, Makkai T (1991) Testing An Expected Utility Model If Corporate Deterrence. Law \& Society Review 25, 7-40.

Carlsmith JM, Gross AE (1969) Some Effects of Guilt on Compliance. Journal of Personality and Social Psychology 11, 232-239.

CDoA (Colorado Department of Agriculture) (1991) Colorado Revised Statutes. Animal Industry Division, Lakewood, CO. (Title 35, Article 24.5: Aquaculture, Sections 35-24.5-101 to 35-24.5111).

CDoA (Colorado Department of Agriculture) (1992) Rules Pertaining to the Administration and Enforcement of the Colorado Aquaculture Act. Animal Industry Division, Lakewood, CO. (8 CCR 1201-21.)

CDoW (Colorado Division of Wildlife) (1991) Colorado Revised Statutes: Wildlife and Parks and Recreation. Colorado Division of Wildlife, Lakewood, CO. (Title 33, Section 33-5.5-101: Fish Health Board Statute.)

CDoW (Colorado Division of Wildlife) (2009) Chapter 00 - General Provisions. Colorado Division of Wildlife, Denver, CO. (Title VII: Aquatic Wildlife.)

Crawford SES, Ostrom E (1995) A Grammar of Institutions. American Political Science Review 89, 582-600.

Firestone J, Kempton W, Krueger A, Loper CE (2004) Regulating Offshore Wind Power and Aquaculture: Messages from Land and Sea. Cornell Journal of Law and Public Policy 14, 71-111.

Freedman JL, Wallington SA, Bless E (1967) Compliance Without Pressure: The Effect of Guilt. Journal of Personality and Social Psychology 7, 117-124.

Frey BS (1994) How Intrinsic Motivation is Crowded Out and In. Rationality and Science 6, 334-352.

Grasmick HG, Bursik RJ Jr (1990) Conscience, Significant Others, and Rational Choice: Extending the Deterrence Model. Law \& Society Review 24, 837-861.

Hatcher S, Jaffry S, Thebaud O, Bennett E (2000) Normative and Social Influences Affecting Compliance with Fishery Regulations. Land Economics 76, 448-461.

Hirschman AO (1985) Against Parsimony: Three Easy Ways of Complicating Some Categories of Economic Discourse. Economics and Philosophy 1, 16-19.

Levi M (1988) Of Rule and Revenue. University of California Press, Berkeley, CA.

Mansbridge J (1994) Public Spirit in Political Systems. In: Aaron HJ, Mann TE, Taylor T (eds) Values and Public Policy, pp. 146-172. Brookings Institution, Washington, DC.

May PJ (2005) Compliance Motivations: Perspectives of Farmers, Homebuilders, and Marine Facilities. Law \& Policy 27, 317-347.

McKeown B, Thomas D (1988) Q Methodology. Sage Publications, Newbury Park, CA.

Naylor RL, Williams SL, Strong DR (2001) Aquaculture - A Gateway for Exotic Species. Science 294, 1655-1656.

Offe C, Wisenthal H (1980) Two Logics of Collective Action: Theoretical Notes on Social Class and Organizational Form. Political Power and Social Theory 1, 67-115.

Olson M (1991) The Role of Morals and Incentives in Society. In: Earley JE (ed) Individuality and Cooperative Action, pp. 117-128. Georgetown University Press, Washington, DC.

Ostrom E (1990) Governing the Commons: The Evolution of Institutions for Collective Action. Cambridge University Press, New York, NY.

Ostrom E (2005) Understanding Institutional Diversity. Princeton University Press, Princeton, NJ.

Schlüter A, Theesfeld I (2010) The Grammar of Institutions: The Challenge of Distinguishing between Strategies, Norms, and Rules. Rationality and Society 22, 445-475.

Scholz JT, Pinney N (1995) Duty, Fear, and Tax Compliance: The Heuristic Basis of Citizenship Behavior. American Journal of Political Science 39, 490-512. 
Siddiki S, Weible CM, Basurto X, Calanni J (2011) Dissecting Policy Designs: An Application of the Institutional Grammar Tool. Policy Studies Journal 39, 79-103.

Simon HA (1985) Human Nature in Politics: The Dialogue of Psychology with Political Science. American Political Science Review 79, 293-304.

Speer J (2008) Why Participatory Service Governance Remains An Empty Promise: An Application of the Grammar of Institutions to Guatemala's Development Council Law. Working Paper presented at the Mini-conference of the Seminar on Institutional Analysis and Development ( $\mathrm{Y}$ 673) at the Workshop in Political Theory and Policy Analysis, 12 Jan 2008, Bloomington, Indiana.

Sutinen JG, Kuperan K (1999) A Socio-Economic Theory of Regulatory Compliance. International Journal of Social Economics 26, 174-193.

United States Department of Agriculture (2006) Census of Aquaculture 2005. [Last accessed 27 Oct 2010.] Available from URL: http://www.agcensus.usda.gov/Publications/2002/Aquaculture/ aquacen2005_01.pdf.

United States Geological Survey (Last Modified 1996) Glossary of Water Use Terminology. [Last accessed 15 Jun 2009.] Available from URL: http://water.usgs.gov/watuse/wuglossary.html.

Zimring FE, Hawkins G (1973) Deterrence: The Legal Threat in Crime Control. University of Chicago Press, Chicago, IL.

\section{Appendix}

\section{Sample interview questions}

These are sample interview questions based on the coding of policies using the Institutional Grammar Tool.

\section{Attribute interview question}

You are one of the people [in terms of position] most often referred to in this legislation. Does this accurately reflect your level of involvement in the aquaculture industry? Probe: Given your knowledge of the aquaculture community, do you think [modal attribute] is the appropriate target audience? Probe: Please describe why or why not. Probe: If not, please describe who you think should be. Probe: Who are the other people [in terms of position] that you think are most involved in aquaculture in the State?

\section{Object interview question}

You are/are not listed in relation to many "items." For example, [object 1, object 2, etc.]. How do you think this reflects the scope of activities that you are involved in on a daily basis?

\section{Deontic and aim interview question}

Some of the prescribed processes assigned to you in the legislation include [X]. How do you interpret different prescriptive operators in relation to these [may/may not/must/ must not]? Probe: When you see a "may" and "may not" in the legislation, versus a "must" or "must not," what factors influence your decision to perform the directive or not?

\section{Condition interview question}

How do prescribed conditions influence how you interpret these?

Or else interview question

I noticed there are not a lot of sanctions described in the legislation for instances in which compliance is not achieved. Why do you think this is the case? 